\title{
Probing discrete auroral arcs by ionospheric tomography
}

\author{
J. Moen ${ }^{1}$, S. T. Berry ${ }^{2}$, L. Kersley ${ }^{2}$, B. Lybekk ${ }^{3}$ \\ ${ }^{1}$ The University Courses on Svalbard (UNIS), PO Box 156, N-9170 Longyearbyen, Norway \\ ${ }^{2}$ Department of Physics, University of Wales, Aberystwyth, Ceredigion, SY23 3BZ, UK \\ ${ }^{3}$ Department of Physics, University of Oslo, PO Box 1048, Blindern, N-0316 Oslo, Norway
}

Received: 29 September 1997 / Revised: 3 February 1998 / Accepted: 4 February 1998

\begin{abstract}
Optical observations of $557.7 \mathrm{~nm}$ and $630.0 \mathrm{~nm}$ emissions from discrete auroral arcs in the post-noon sector have been related to localised field-aligned enhancements in the spatial distribution of E- and Flayer electron density respectively seen in images reconstructed by ionospheric tomography. Results from two case studies are presented in which meridian scanning photometer and all-sky camera observations on Svalbard have been compared to electron-density structures found by tomographic inversion of measurements made by reception of radio signals at a chain of four stations at high latitude. The F-layer features are long-lived and show exact correspondence to the red-line emissions. Transient arcs in green-line intensity result in E-region structures that are resolved in one case, but not in another where the dynamic auroral forms are separated by less than one degree of latitude. The signature of an inverted- $\mathrm{V}$ precipitation event is clearly evident in one example.
\end{abstract}

Key words. Ionosphere (Auroral ionosphere) ·

Magnetospheric physics (Auroral phenomena) · Radio science (Ionospheric physics)

\section{Introduction}

Narrow multiple discrete arcs, aligned in the magnetic east-west direction, are a regular feature of post-noon dayside auroral activity (Meng and Lundin, 1986; Evans, 1985). Such auroral behaviour occurs in the afternoon sector characterised by a maximum in the region 1 upward field-aligned current (Iijima and Potemra, 1978). Evans (1985) found from satellite data

Correspondence to: L. Kersley analysis that precipitating electrons in the energy range $0.3-3 \mathrm{keV}$ carried the current out of the ionosphere in latitudinally thin structures ( $\sim 20 \mathrm{~km}$ average width) in this local time sector. Robinson et al. (1984) presented incoherent scatter measurements of an ionospheric Fregion density enhancement attributed to an upward field-aligned current. They concluded that the associated electron beam located at the electric field reversal, produced a region of enhanced electron density by a process similar to that established for evening sector auroral arcs, but with less energetic electrons.

Several magnetosphere-ionosphere current coupling models exist to explain the formation of dayside multiple arc structures. Examples include the boundary layer dynamo model of Lundin and Evans (1985), who describe arc formation as a consequence of solar-wind filaments with excess momentum penetrating a closedmagnetosphere boundary layer. Polarisation within the layer results in field-aligned discharge currents closing in the ionosphere. A sequence of plasma filaments, where negative space charges build up, may map along upward field-aligned current sheets to the latitudinally thin, multiple discrete arcs in the ionosphere (Lundin and Evans, 1985). Another model describes multiple arc formation in the post-noon sector as a mapping of flux transfer events into the ionosphere (Crooker and Siscoe, 1990). As a patch of open flux moves away from the subsolar point, the ionospheric footprint becomes successively more elongated, resulting in the east-west aligned aurora. The model of Torbert and Mozer (1978) argued that electrostatic shocks in the large-scale region 1 current distribution were responsible for discrete auroral arcs, while Moen et al. (1994) proposed that discrete arcs, observed on convecting field lines equatorward of the convection reversal boundary, could be stimulated by KHI-driven kinetic Alfven waves.

The intention of the present paper is to demonstrate for the first time that the techniques of ionospheric tomography can image electron density structures associated with discrete auroral activity in the post-noon sector. Ionospheric tomography provides a new method 
of reconstructing the spatial distribution of electron density, using radio transmissions from satellites. Current-linked beams of electrons cause direct-impact ionisation that can be imaged by the tomographic technique. Results are presented of both F- and Eregion enhancements in electron density that are related spatially to auroral emissions at $630.0 \mathrm{~nm}$ and $557.7 \mathrm{~nm}$ observed by ground-based optical instrumentation.

\section{Instrumentation}

\subsection{Ionospheric tomography}

Ionospheric tomography uses a chain of satellite receivers sited approximately along a line of geographic longitude. Phase-coherent radio signals on $150 \mathrm{MHz}$ and $400 \mathrm{MHz}$, transmitted by the polar orbiting satellites in the Navy Navigational Satellite System (NNSS), are used to measure the total electron content (TEC) along many intersecting satellite-to-receiver ray paths. An inversion algorithm is then employed to reconstruct the spatial variation in electron density as a function of latitude and height. Further information on the development of experimental ionospheric tomography can be found in Kersley and Pryse (1994), with more recent results reported by Walker et al. (1996) and Kersley et al. (1997). The reconstructions described in this study were performed using a variation of the discrete inverse theory (DIT) method of Fremouw et al. (1992), modified to use Chapman profiles as a background containing large-scale features upon which the algebraic reconstruction technique (ART) was used to generate the final image (Gordon et al., 1970).

For the present work four satellite receiving systems were located at Tromsø $\left(69.8^{\circ} \mathrm{N}, 19.0^{\circ} \mathrm{E}\right)$, Bjørnøya $\left(74.5^{\circ} \mathrm{N}, 19.0^{\circ} \mathrm{E}\right)$, Longyearbyen $\left(78.2^{\circ} \mathrm{N}, 15.3^{\circ} \mathrm{E}\right)$ and $\mathrm{Ny}$ Alesund $\left(78.9^{\circ} \mathrm{N}, 11.9^{\circ} \mathrm{E}\right)$. Figure 1 shows the geographic locations of the receiving stations. The observations discussed here were obtained in December 1996, at times when corresponding ground-based optical data were available from Ny Ålesund and Longyearbyen.

\subsection{Optical instrumentation}

The optical instumentation employed in this work included a meridian scanning photometer (MSP) located at $\mathrm{Ny}$ Ålesund, and a pair of all-sky cameras at Longyearbyen. The MSP scanned along the geomagnetic meridian to $10^{\circ}$ above each horizon with a period of $18 \mathrm{~s}$ identifying auroral emissions as a function of zenith angle. The MSP was sensitive to the auroral green $(557.7 \mathrm{~nm})$ and red $(630.0 \mathrm{~nm})$ lines. The instrument thus examined the north-south motion of auroral features, with the all-sky cameras providing additional information on the east-west extent and the dynamical behaviour of the discrete forms. The first of the latter devices comprised a simple low-light television (TV) camera recording the total light emitted by auroral activity, from which images were digitised. The second device was an all-sky CCD imager, fitted with a $630.0 \mathrm{~nm}$ interference filter to image only red-line forms, recording an image every $20 \mathrm{~s}$ with an exposure time of $2 \mathrm{~s}$.

\section{Observations}

\subsection{December 1996}

Figure 2 shows stacked photometer plots for both $630.0 \mathrm{~nm}$ and $557.7 \mathrm{~nm}$ auroral emissions recorded at Ny Ålesund on 10 December 1996, in the time interval 13:39 UT to 13:52 UT (about 17:00 MLT). Each line trace represents the intensity at the appropriate wavelength across the viewing sweep of the MSP, which roughly represents the geomagnetic meridian. The plots show that auroral activity was dominated by bright multiple discrete forms in the green-line channel. The red line exhibits similar behaviour, but with considerably less variation in intensity. Figure 3 shows a red-filtered allsky camera image at 13:46 UT mapped on to a geographic plane assuming an emission altitude of $250 \mathrm{~km}$. The path of the NNSS satellite monitored by the ground receivers and crossing $75^{\circ} \mathrm{N}$ at 13:48 UT, is indicated on the image. The dominant feature seen is the bright auroral arc aligned east-west above and to the south of Ny Alesund corresponding to activity identified in the MSP plot. Although the satellite pass over the region lasted around $20 \mathrm{~min}, 13: 46$ UT has been selected

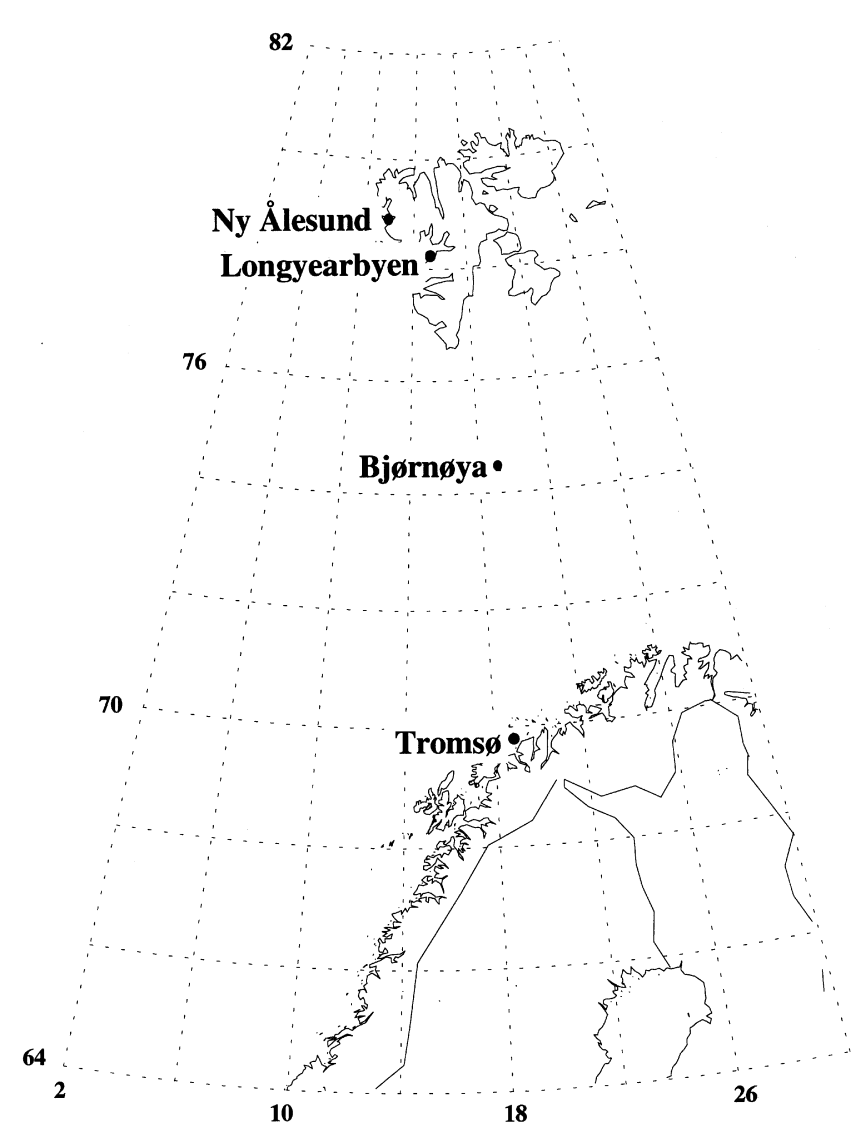

Fig. 1. Map showing satellite receiving system locations 


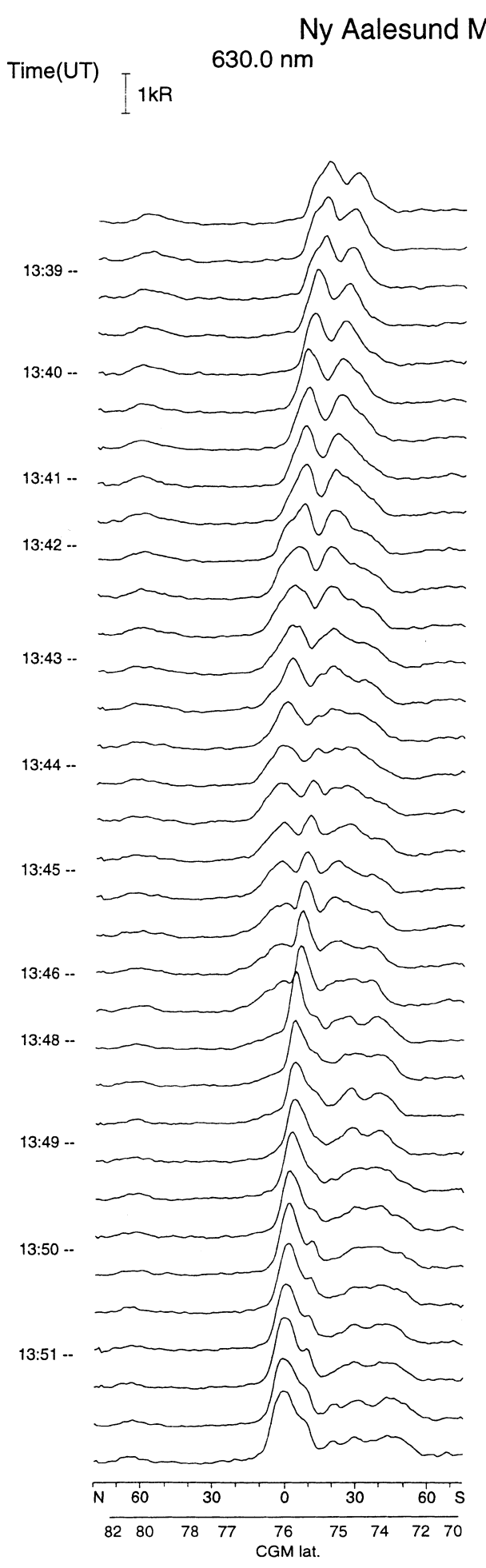

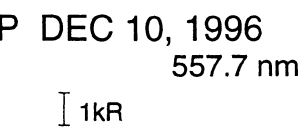

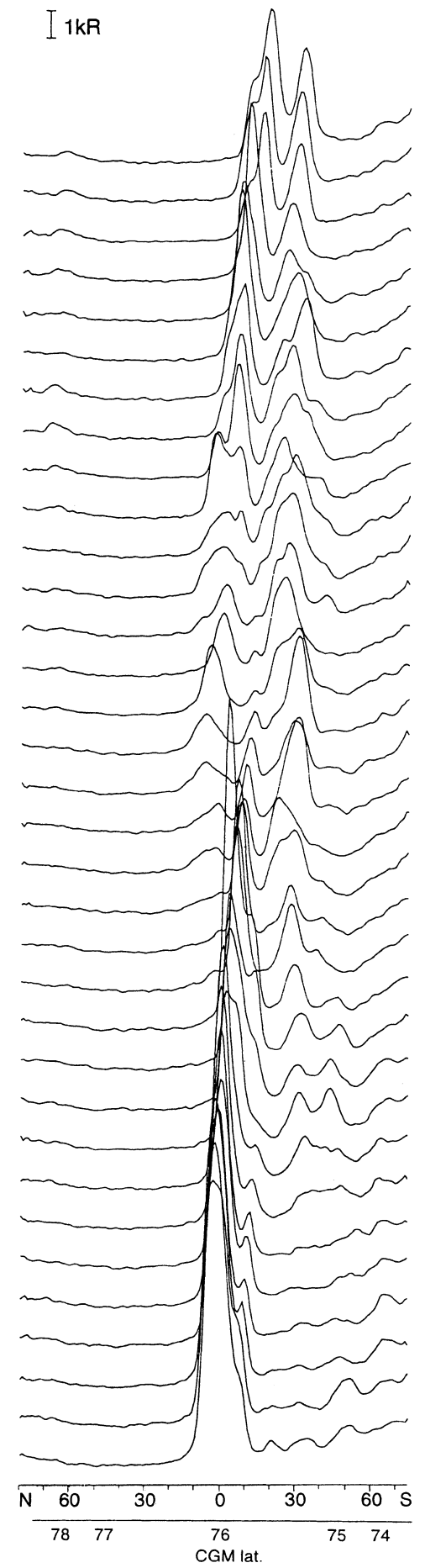

Fig. 2. Meridian scanning photometer data from 10 December 1996. Plot shows auroral emission intensities as a function of zenith angle for the $630.0 \mathrm{~nm}$ and $557.7 \mathrm{~nm}$ channels. A corresponding CGM scale has been superimposed on the plot in Fig. 3 to represent the conditions when the measurements were made that were used for tomographic reconstruction in the vicinity of the auroral features. The satellite was southbound, so that about 13:39 UT the ray path to the receiver at Tromsø was intersecting the Fregion while that for Bjørnøya cut through the E-layer, both above Svalbard. It is these rays that were giving information about the vertical structure of the ionisation to the tomographic process. However, much of the detail of the horizontal extent of the field-aligned ionisation above Svalbard was obtained from quasi-vertical ray paths to the receivers at Ny Ålesund and Longyearbyen in a narrow time interval around 13:46 UT.

The resulting tomographic reconstruction is shown in Fig. 4. The image has been plotted over the latitudinal range $75^{\circ}$ to $80^{\circ} \mathrm{N}$ to illustrate the main features of the polar ionosphere at this time. The dominant structures are an intense region of auroral-E ionisation around 


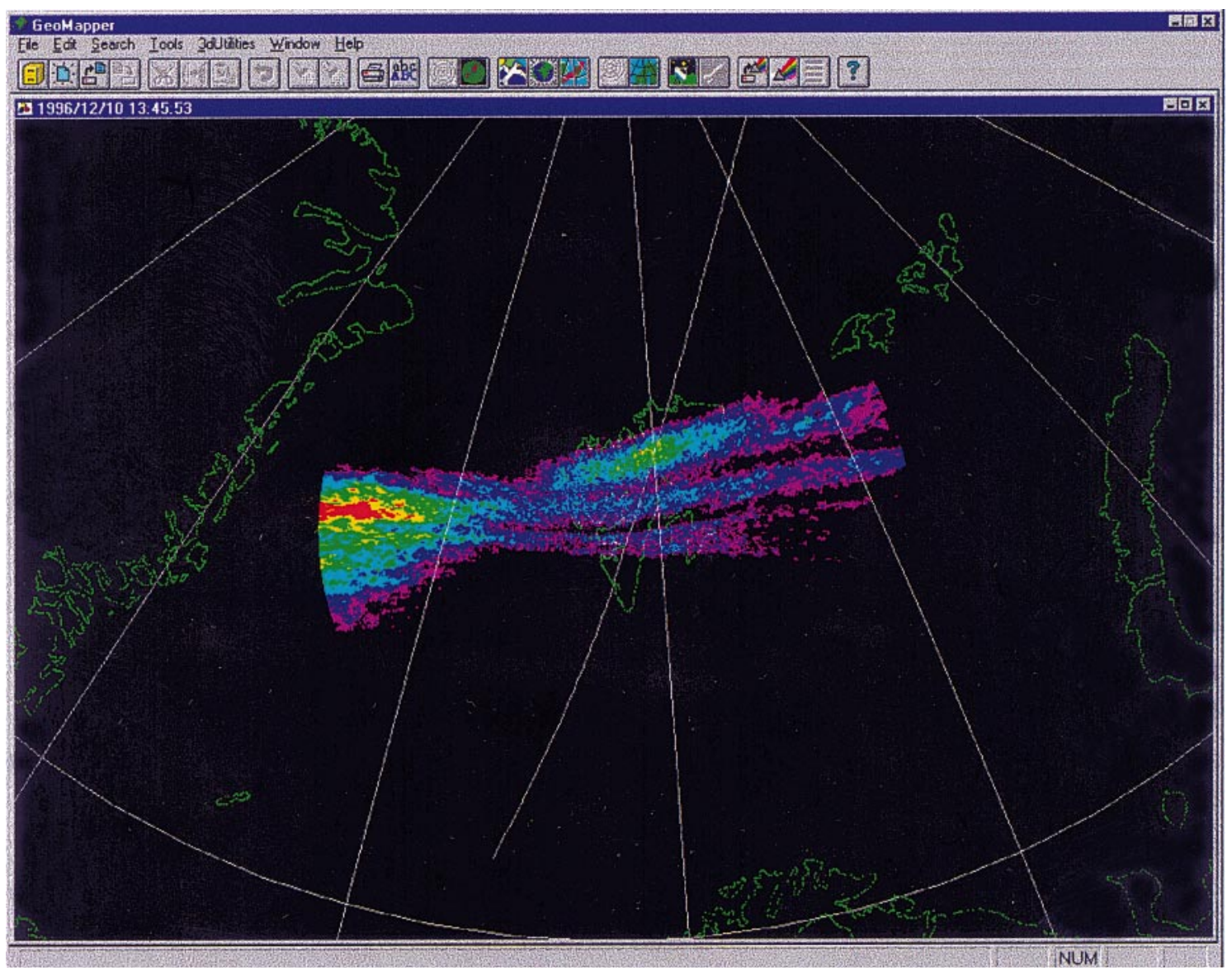

Fig. 3. Red-line emission all-sky camera image from Longyearbyen mapped onto a geographic plane assuming an emission altitude of $250 \mathrm{~km}$ at 13:46 UT on 10 December 1996. The path of the NNSS satellite pass crossing $75^{\circ} \mathrm{N}$ at 13:48 UT is indicated on the figure by the line from northeast to southwest

may map to the enhanced green-line intensity toward the southern horizon. The region of increased plasma density near the F-layer peak covers essentially a similar latitudinal range as the enhanced red-line emission intensity. In addition, strong brightening just south of Ny Ålesund at around 13:46 UT in Fig. 2 relates well to the strong localised field-aligned increase in F-layer density imaged between Ny Ålesund and Longyearbyen. It must be remembered that the tomographic image is created from measurements made over a period of several minutes. The reconstruction process implicitly assumes that the electron-density structure is unchanging during this time. It is clear from the MSP observations that there were dynamic variations in the fine structure of the broader arc, with localised brightenings in luminosity and latitudinal motion in the location of the discrete features. The lack of fine structure and latitudinal broadening of the E-layer blob over Svalbard may have resulted from spreading of the image in a highly dynamic situation.

\subsection{December 1996}

A second case study uses observations from 17 December 1996, where the southbound satellite pass crossed resolved in the density image. The reconstruction has also imaged a weak underlying E-layer to the south that 
Tomographic Image: 10/12/96 13:48 UT Electron Density $\left(\mathrm{x} 10^{11} \mathrm{~m}^{-3}\right)$

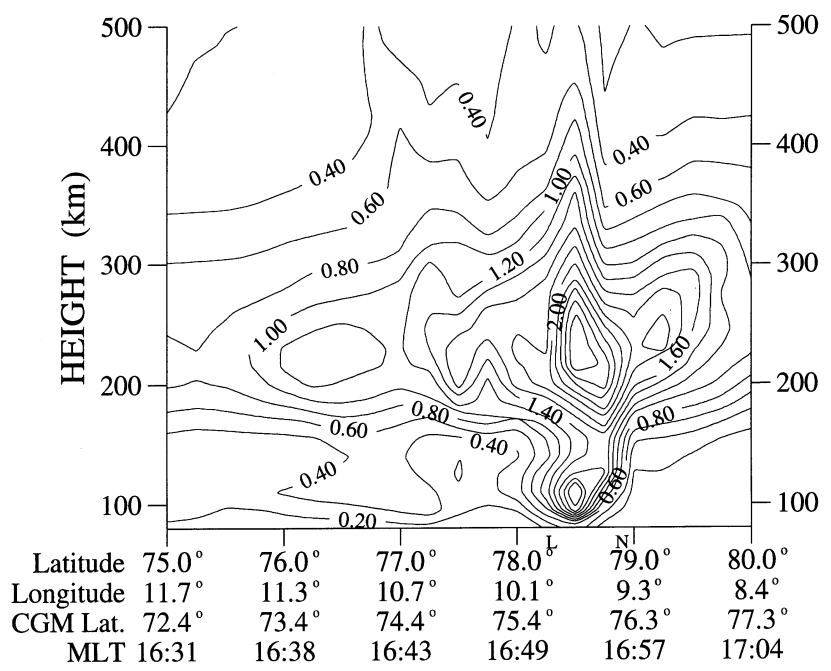

Fig. 4. Tomographic image of electron density for a satellite pass at 13:48 UT on 10 December 1996. The latitudes of Longyearbyen and Ny Ålesund are denoted by the letters $L$ and $N$ respectively

$75^{\circ} \mathrm{N}$ at 12:06 UT. The appropriate MSP plot is shown in Fig. 5, with the region of interest being from around 11:58 to 12:04 UT with the most important information for the tomographic image over Svalbard coming from the last few minutes of this interval. Again, low intensity red-line emissions cover the field of view from zenith towards the south, though before noon a feature is also seen to the north. Some structuring is also found within the band, with two discrete enhancements from 12:01 to 12:04 UT, a time interval of particular interest here. Bright discrete arcs with at least two components are seen after midday in the $557.7 \mathrm{~nm}$ channel to the south of the observing site. The multiple east-west alignment of auroral activity is clearly displayed in the all-sky camera image in Fig. 6, where the total auroral intensity has been overlaid on a geographic projection assuming an emission altitude of $120 \mathrm{~km}$. The dominant features are the pair of narrow arcs above and to the south of the viewing site in Longyearbyen, and a weaker, broader band over the northern portion of Svalbard.

The corresponding tomographic reconstruction is shown in Fig. 7. An auroral E-region extends over the Svalbard sites with a localised strong maximum just south of Longyearbyen and a second, less intense maximum just south of Ny Ålesund. There are several prominent F-layer enhancements with one overhead and one to the south of Longyearbyen, both with peak densities of $2 \times 10^{11} \mathrm{~m}^{-3}$. Another structured feature lies above and to the north of $\mathrm{Ny} \AA$ Alesund.

Comparing the MSP plots (Fig. 5) and the electron densities (Fig. 6), the essentially twin peaked-structure of the green-line emission around 12:02 UT can be linked directly to the two enhancements in E-layer density seen in the tomographic image. The arc just south of Ny Ålesund is the more stable feature that maps to the narrower enhancement in plasma concen- tration. The more dynamic arc around $75^{\circ} \mathrm{N}$ CGM maps to the broader blob in E-layer density seen above Longyearbyen. A transient feature in the $557.7 \mathrm{~nm}$ intensity seen between $74^{\circ} \mathrm{N}$ and $75^{\circ} \mathrm{N}$ around noon may be linked to the weaker extension of the E-layer density in that region, while the earlier brightening transient to the north may have its counterpart in the form of the $0.2 \times 10^{11} \mathrm{~m}^{-3}$ E-layer contour at the northern extremity of Fig. 6.

The structure of the F-region near the layer peak seen in Fig. 6 can be related to the enhancements in $630.0 \mathrm{~nm}$ luminosity observed by the MSP (Fig. 5). The twin apparently field-aligned features above and to the south of Longyearbyen respectively align directly with the two auroral arcs found in the 12:01 UT to 12:04 UT time interval. Before noon there had been a brightening of an auroral form to the north of Ny Alesund that may be linked to the F-layer density enhancement at the north of the plot, while the very weak feature overhead at $73^{\circ} \mathrm{N}$ CGM may represent a signature in the ionisation related to the transient increase in red-line intensity at this latitude after 11:58 UT.

\section{Discussion}

Examples have been presented of observations of discrete auroral forms in the post-noon sector and their links to ionisation at both E- and F-layer altitudes. The tomographic reconstructions of electron density have resolved discrete ionisation blobs in both height regimes. In the first case for 10 December 1997, an intense Eregion feature was imaged, underlying a latitudinally broader F-region enhancement containing a narrow, apparently field-aligned structure. On 17 December 1997, the results showed a more extended E-region containing evidence of fine structure with a complex series of higher altitude F-region blobs.

Roble and Rees (1977) modelled the ionospheric electron density response to various precipitation conditions. Their model for dayside precipitation, dominated by low-energy (100-300 eV) electrons, demonstrated that the peak ionisation rate occurred at an altitude of around $250 \mathrm{~km}$. Based on a dark ionosphere without solar ionisation input, the F-region density reached a steady state within $20 \mathrm{~min}$ of the precipitation onset. However, the $630.0 \mathrm{~nm}$ line auroral emission, caused primarily by secondary electron impact and with the lifetime of the OI ${ }^{1} \mathrm{D}$ state of $110 \mathrm{~s}$, reaches a maximum intensity around $3 \mathrm{~min}$ after the start of the precipitation (Roble and Rees, 1977), so that the red-line activity can be used as an indicator of ongoing ionisation processes. The lower altitude E-region is essentially unaffected by soft-particle precipitation, as the stopping altitude for particles of these energies restricts activity to the F-region. Simulation of the ionospheric response to a particle spectrum peaking at energies greater than $1 \mathrm{keV}$ showed that the ionisation rate achieved a peak at an altitude of $120 \mathrm{~km}$ with a corresponding rapid rise in E-region electron density. The F-region response is slower, and although the E-region recovers very swiftly 
when precipitation ceases, residual density remains at greater altitudes for some time.

The post-noon sector is characterised by the fieldaligned current activity, with discrete arcs resulting from $\mathrm{keV}$ precipitation. The particle energy spectrum contains a significant component of soft electrons that contribute at a slower rate to the F-region ionisation observed in the tomographic technique. The lifetime of F-region ionisation means, that in some cases, a direct correlation between $630.0 \mathrm{~nm}$ optical events and electron density features may not be exact as convective motion drives features away from the precipitation source, and thus the location of the auroral activity. It is, therefore, possible that some of the density features seen here were caused by auroral events occurring prior to the tomography observations. This is probably the case in the image for 17 December (Fig. 7), where the structure in the F-layer extending north from around

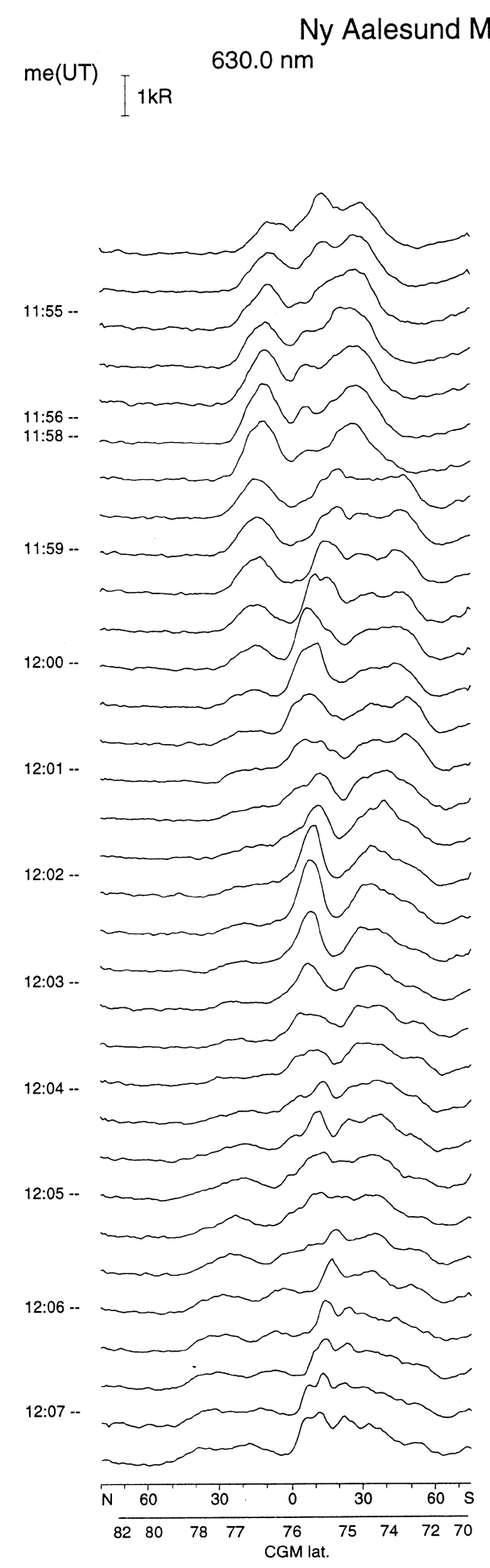

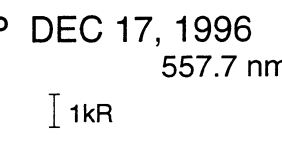

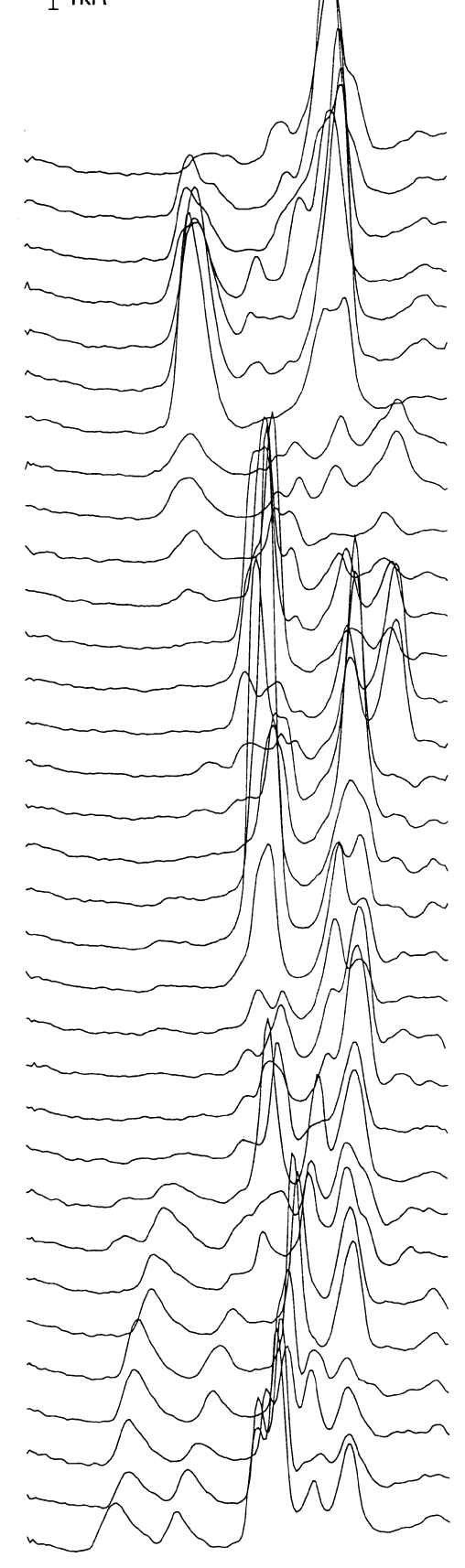

Fig. 5. Meridian scanning photometer data from 17 December 1996 for $630.0 \mathrm{~nm}$ and $557.7 \mathrm{~nm}$ channels with corresponding CGM 


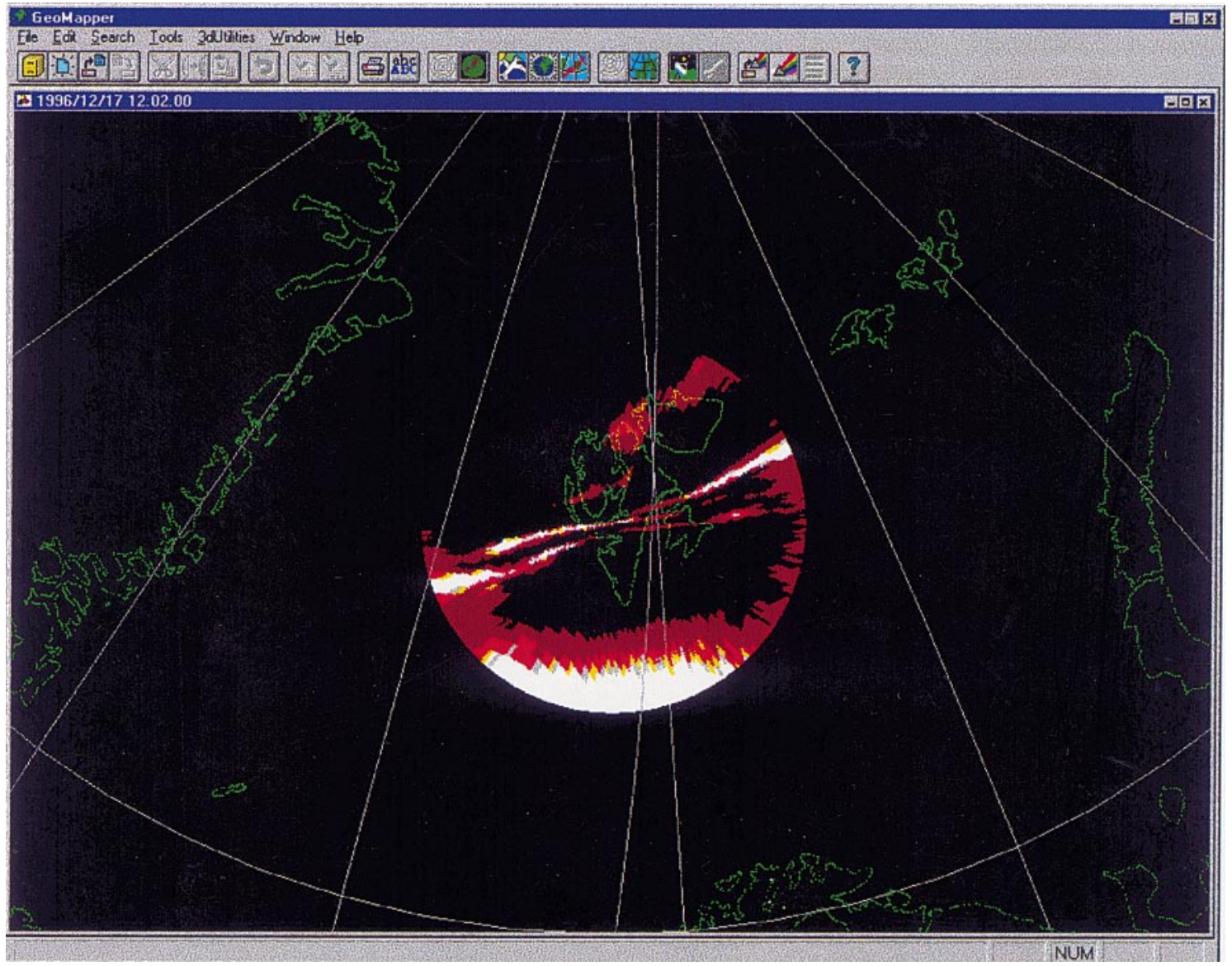

Fig. 6. Total auroral emission all-sky TV camera image from Longyearbyen at 12:02 UT on 17 December 1996, mapped on to a geographic plane assuming an emission altitude of $120 \mathrm{~km}$. The path of the NNSS satellite pass crossing $75^{\circ} \mathrm{N}$ at 12:06 UT, is indicated by the line running from northeast to southwest on the figure

\section{Tomographic Image: 17/12/96 12:06 UT \\ Electron Density $\left(\mathrm{x} 10^{11} \mathrm{~m}^{-3}\right)$}

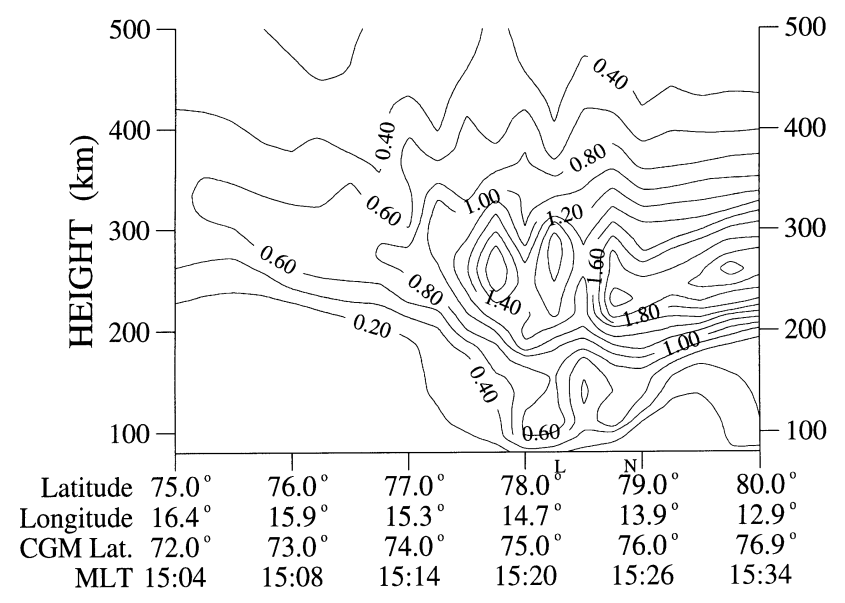

Fig. 7. Tomographic image of electron density for a satellite pass at 12:06 UT on 17 December 1996. The latitudes of Longyearbyen and Ny Alesund are denoted by the letters $L$ and $N$ respectively

$79^{\circ} \mathrm{N}$ appears to have been smeared latitudinally. Analysis of the MSP data reveals that long-lived auroral activity had occurred in this region some minutes previously but was in rapid decay as the tomography satellite pass began. The latitudinally extensive ionisation enhancement is thus interpreted as the remnant of earlier ionisation processes, though subject to F-region plasma motion convecting it from the site of origin. Plasma drift is less important at E-region altitudes as the enhanced plasma features are constrained by collisions with neutral species during their comparatively short lifetime.

Energetic particles accelerated through a potential difference as part of the upward field-aligned current near the convection reversal boundary, give rise to ionisation. It is this ionisation that results in the E- and F-region features, imaged by the tomographic technique, that are coincident with the auroral features observed by ground-based optical instrumentation. Robinson et al. (1984), using the Sondre Stromfjord incoherent scatter radar, studied an F-region ionisation enhancement with a peak height of around $250 \mathrm{~km}$ associated with an upward field-aligned current populated by $350 \mathrm{eV}$ electrons. The density of the enhancement was around $2 \times 10^{11} \mathrm{~m}^{-3}$, comparable to the Flayer peak densities measured in the structures reconstructed in the tomographic images of the present study.

It has already been noted that the tomographic reconstruction was unable to resolve discrete structures 
in E-layer density for the major feature seen on 10 December 1996, although the $557.7 \mathrm{~nm}$ emissions showed evidence for discrete though unstable auroral activity within a latitudinal band of about $1^{\circ}$. There was a long-lived system of two arcs occurring in very close proximity separated by around $10^{\circ}$ in the MSP field of view. More importantly, the pair of auroral features move gradually poleward, with some individual motion of the arc positions about a central line, accompanied by an intensification in $557.7 \mathrm{~nm}$ brightness. It seems likely that this motion has blurred the resolution of the tomographic image, resulting in only the single, rather broader enhancement that appears in the E-region reconstruction. During very active conditions, considerable latitudinal motion of the current sheet and subsequently of $557.7 \mathrm{~nm}$ emissions can be expected so that multiple arcs may likely result in only an averaged view of E-region structure in the tomographic reconstructions. Poleward current motion in the present case may also have affected the F-region structure, which combined with probable plasma drift may have created the broad $\left(\sim 3^{\circ}\right.$ latitude) feature.

Considerably less latitudinal motion of the green-line aurora was apparent on 17 December 1997, resulting in the resolution of the E-region features. The essentially more stable position of at least one of the arcs in this instance during the time of interest, and their separation by around $20^{\circ}$ in the MSP field of view, results in a clear resolution of the features in the tomographic image. In addition, the southernmost enhancement is the stronger, reflecting the more persistent optical behaviour.

The main pair of F-region density enhancements imaged on 17 December 1996 straddle a line that approximates to the direction of the magnetic field line through the E-layer maximum, in a general formation that resembles the ionospheric signature of an inverted-V event. Rino et al. (1983) demonstrated that inverted-V events of soft-particle precipitation could cause 'upright-V' ionospheric signatures, with twin blobs of enhanced electron density in the F-region. For precipitating electrons in the energy range $0.3-3 \mathrm{keV}$, as expected in the post-noon sector (Evans, 1985), the harder precipitation component will generate localised green E-region aurora. With rapid loss processes at lower altitudes, the density pattern spreads out latitudinally with increasing height, possibly resolving into a pair of F-region blobs caused by the softer precipitation affecting the higher altitudes. It is possible that the structure above $75^{\circ} \mathrm{CGM}$ on 17 December 1996 is such an event.

\section{Conclusion}

The new experimental technique of ionospheric tomography enables monitoring of the spatial structure of electron density. The present work has demonstrated the success of the method in probing features associated with auroral precipitation at both E- and F-region altitudes. The discrete auroral arcs studied here occur in the post-noon sector of the region 1 current system. The results demonstrate that ionospheric tomography offers a new tool for routine monitoring of the ionospheric signatures of the effects of field-aligned currents in the afternoon sector. The positions of field-aligned auroral features are well represented in the tomographic reconstructions, although further work is needed to characterise fully the arc signatures in the tomographic images. The technique may then have the potential to investigate the circumstances of whether or not discrete auroral arcs occur in daylight (Newell et al., 1996).

Acknowledgements. This project has been given financial support from the University Courses on Svalbard (UNIS grant 9/963), from 'Nansenfondet' (grant 21/97), and grants from the Research Council of Norway and the British Council under the Scholarship Scheme for Collaboration Research Projects between Norway and Britain in 1997. Optical observation campaigns in Ny Ålesund have benefited from technical support from the Norwegian Polar Research Institute. Thanks also to Dr. K. Hayashi for all-sky TV camera recordings made in Longyearbyen.

The ionospheric tomography experiment is supported by the UK Particle Physics and Astronomy Research Council under grant GR/K98797. STB is a PPARC research student and acknowledges support from that body for an extended field trip to UNIS. The assistance of the University of Tromso and the Norwegian Polar Research Institute in the experimented observations is acknowledged with thanks.

Topical Editor D. Alcaydé thanks P.E. Sandholt and A. Brekke for their help in evaluating this paper.

\section{References}

Crooker, N. U., and G. L. Siscoe, On mapping flux transfer events to the ionosphere, J. Geophys. Res., 95, 3795-3799, 1990.

Evans, D. S., The characteristics of a persistent arc at high latitude in the 1400 MLT sector, in The polar cusp, Ed. J. Holtet and A. Egeland, pp. 99-109, D. Reidel, Norwell, Mass., 1985.

Fremouw, E. J., J. A. Secan, and B. M. Howe, Application of stochastic inverse theory to ionospheric tomography, Radio Sci., 17, 721-732, 1992.

Gordon, R., R. Bender, and G. T. Herman, Algebraic reconstruction techniques (ART) for three-dimensional electron microscopy and X-ray photography, J. Theor. Biol., 29, 471-481, 1970.

Iijima, T., and T. A. Potemra, Large-scale characteristics of fieldaligned currents associated with substorms, J. Geophys. Res., 83, 599-615, 1978.

Kersley, L., and S. E. Pryse, The development of experimental ionospheric tomography, Int. J. Image Syst. Technol., 5, 141147, 1994.

Kersley, L., S. E. Pryse, I. K. Walker, J. A. T. Heaton, C. N. Mitchell, M. J. Williams, and C. A. Willson, Imaging of electron density troughs by tomographic techniques, Radio Sci., 32, 1607-1621, 1997.

Lundin, R., and D. S. Evans, Boundary layer plasmas as a source for high-latitude, early afternoon, auroral arcs, Planet. Space Sci., 33, 1389-1406, 1985.

Meng, C. I., and R. Lundin, Auroral morphology of the midday oval, J. Geophys. Res., 91, 1572-1584, 1986.

Moen, J., P. E. Sandholt, M. Lockwood, A. Egeland, and K. Fukui, Multiple discrete arcs on sunward convecting field lines in the 14-15 MLT region, J. Geophys. Res., 99, 6113-6123, 1994.

Newell, P. T., C. I. Meng, and K. M. Lyons, Suppression of discrete aurorae by sunlight, Nature, 381, 766-767, 1996.

Rino, C. L., R. C. Livingston, R. T. Tsunoda, R. M. Robinson, J. F. Vickrey, C. Senior, M. D. Cousins, and J. Owen, Recent studies 
of the structure and morphology of auroral zone $\mathrm{F}$ region irregularities, Radio Sci, 18, 1167-1180, 1983.

Robinson, R. M., D. S. Evans, T. A. Potemra, and J. D. Kelly, Radar and satellite measurements of an F-region enhancement in the post-noon sector, Geophys. Res. Lett., 9, 899-902, 1984.

Roble, R., G., and M. H. Rees, Time-dependent studies of the aurora: Effects of particle precipitation on the dynamic morphology of ionospheric and atmospheric properties, Planet. Space. Sci., 25, 991-1010, 1977.

Torbert, R. B., and F. S. Mozer, Electrostatic shocks as the source of discrete arcs, Geophys. Res. Lett., 5, 135-138, 1978.

Walker, I. K., J. A. T. Heaton, L. Kersley, C. N. Mitchell, S. E. Pryse, and M. J. Williams, EISCAT verification in the development of ionospheric tomography, Ann. Geophysicae, 14, 1413-1421, 1996. 